\title{
EPO-releasing neural precursor cells promote axonal regeneration and recovery of function in spinal cord traumatic injury
}

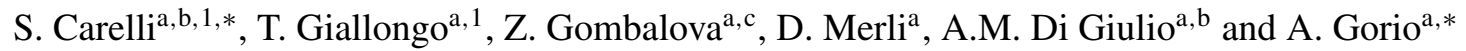 \\ ${ }^{a}$ Department of Health Sciences, Laboratory of Pharmacology, University of Milan, via A di Rudinì, Milan, Italy \\ ${ }^{\mathrm{b}}$ Pediatric Clinical Research Center Fondazione Romeo ed Enrica Invernizzi, University of Milan, Milan, Italy \\ ${ }^{\mathrm{c}}$ Pavol Jozef Safarik University in Kosice, Faculty of Science, Institute of Biology and Ecology, Moyzesova, \\ Kosice, Slovakia (SVK)
}

\begin{abstract}
.
Background: Spinal cord injury (SCI) is a debilitating condition characterized by a complex of neurological dysfunctions ranging from loss of sensation to partial or complete limb paralysis. Recently, we reported that intravenous administration of neural precursors physiologically releasing erythropoietin (namely Er-NPCs) enhances functional recovery in animals following contusive spinal cord injury through the counteraction of secondary degeneration. Er-NPCs reached and accumulated at the lesion edges, where they survived throughout the prolonged period of observation and differentiated mostly into cholinergic neuron-like cells.

Objective: The aim of this study was to investigate the potential reparative and regenerative properties of Er-NPCs in a mouse experimental model of traumatic spinal cord injury.

Methods and Results: We report that Er-NPCs favoured the preservation of axonal myelin and strongly promoted the regrowth across the lesion site of monoaminergic and chatecolaminergic fibers that reached the distal portions of the injured cord. The use of an anterograde tracer transported by the regenerating axons allowed us to assess the extent of such a process. We show that axonal fluoro-ruby labelling was practically absent in saline-treated mice, while it resulted very significant in Er-NPCs transplanted animals.

Conclusion: Our study shows that Er-NPCs promoted recovery of function after spinal cord injury, and that this is accompanied by preservation of myelination and strong re-innervation of the distal cord. Thus, regenerated axons may have contributed to the enhanced recovery of function after SCI.
\end{abstract}

Keywords: Spinal cord injury, neural stem cells, transplantation, regenerative medicine, animal behavior

\section{Introduction}

Spinal cord injury (SCI) is most commonly caused by high-energy trauma and represents a complex emergency issue that leads most often to a chronic condition. The majority of patients are men of 16-30

\footnotetext{
${ }^{1}$ Carelli S. and Giallongo T. equally contributed to the work.

*Corresponding authors. Alfredo Gorio and Stephana Carelli, Department of Health Sciences University of Milan, Laboratory of Pharmacology, Polo H. San Paolo, via A di Rudinì 8, 20142 Milan, Italy. Tel.: +39 0250323030; Fax: +39 0250323033; E-mails: alfredo.gorio@unimi.it (Alfredo Gorio) and stephana.carelli@guest.unimi.it (Stephana Carelli).
}

years of age, thus in addition to the enormous personal suffering, SCI results also in substantial costs to society (Fehlings et al., 2011; Schlayer et al., 1988). There is currently no curative therapy, the care in the acute phase used to be limited to high-dose corticosteroid treatment that is now being advised against, and surgical stabilization and decompression to possibly attenuate further damage (Fehlings et al., 2011; Furlan et al., 2011). Numerous reports have described the presence of inhibiting factors in the lesion environment that limit neural regeneration in adult CNS and in particular across the injury site in SCI. A variety of inhibitory molecules 
associated with myelin and extracellular matrix have been described (Fawcett, 2006; Fitch et al., 2008; He $\&$ Koprivca, 2004). The limiting environmental factors may include also the insufficient local presence of growth-permissive matrices and growth factors. The neutralization of such growth inhibitory molecules have been extensively studied (Young, 2014) and also a variety of stem cells or stem cell-derived molecules as well have shown beneficial effects to a variable extent (Martino \& Pluchino, 2006; Romanko et al., 2007). We had shown that intravenous administration of erythropoietin-releasing adult neural precursors cells, isolated from SVZ six hours after donor death (Er-NPCs; formerly called post mortem-neural precursor cells; PM-NPCs; Marfia et al., 2011), improve hind limb functional recovery. Er-NPCs accumulate at the lesion site, where they differentiate mostly into cholinergic neuron cells, favouring preservation of myelin (Carelli et al., 2014a; Carelli et al., 2014b; Carelli et al., 2015). Acute traumatic SCI is followed by vascular changes with loss of neurons, oligodendroglia, and astrocytes, neuroinflammation quickly follows with consequent invasion of the injury by a variety of inflammatory cells. These acute condition is then associated to Wallerian degeneration of ascending and descending tracts with gradual formation of cavities in the cord, the formation of the glial scar reduces greatly the growth ability by axons across the injury (Gorio et al 2002, Ahuja et al. 2017). The aim of this work was to investigate the ability of Er-NPCs in axonal regeneration across injury. Here, we show, that Er-NPCs administration enhances restauration of TH and 5-HT positive fibres in the caudal cord, and increases significantly the number of axons able to cross the injury site. This enhanced re-innervation of the caudal cord may underlay the gradual and continuous improvement in hind limb function that has been observed even at 90 days after lesioning.

\section{Materials and methods}

\subsection{Animal care}

In this study, adult CD1 male mice $25-30 \mathrm{~g}$ in weight (Charles River, Calco, Italy) were used. All of the procedures were approved by the Review Committee of the University of Milan and met the Italian Guidelines for Laboratory Animals, which conform to the European Communities Directive (2010/63/UE). Animals were kept for at least
3 days before the experiments in standard conditions $\left(22 \pm 2{ }^{\circ} \mathrm{C}, 65 \%\right.$ humidity, and artificial light between 8:00 a.m. to 8:00 p.m.).

\subsection{Er-NPCs isolation, characterization, and labelling}

Er-NPCs were obtained from 6 weeks old CD-1 albino mice; their isolation, growth and characterization were performed by following methods described in previously published papers (Marfia et al., 2011; Carelli et al., 2014a; Carelli et al., 2014b; Carelli et al., 2015) and set up in the past by Gritti and co-workers (Gritti et al., 2002). Briefly, cells were isolated from the SVZ 6 hours after sacrifice by cervical dislocation. Brains were removed, and tissues containing the SVZ region were dissected, transferred to Earl's balanced salt solution (Life Technologies, Monza, Italy) containing $1 \mathrm{mg} / \mathrm{ml}$ papain (27 U/mg; Sigma-Aldrich, Milan, Italy), $0.2 \mathrm{mg} / \mathrm{ml}$ cysteine (Sigma-Aldrich), and $0.2 \mathrm{mg} / \mathrm{ml}$ EDTA (Sigma-Aldrich). Tissue was incubated for $45 \mathrm{~min}$ at $37^{\circ} \mathrm{C}$ on a rocking platform. Tissues were then transferred to DMEM-F12 medium (Euroclone, Pero, Milan, Italy) and mechanically dissociated with a Pasteur pipette. Cells were counted and plated at 3500 cells/cm2 in DMEM-F-12 (Euroclone, Pero, Milan, Italy) containing $2 \mathrm{ml}$-glutamine (Euroclone), $0.6 \%$ glucose (Sigma-Aldrich), $9.6 \mathrm{gm} / \mathrm{ml}$ putrescine (Sigma-Aldrich), $6.3 \mathrm{ng} / \mathrm{ml}$ progesterone (SigmaAldrich), $5.2 \mathrm{ng} / \mathrm{ml}$ sodium selenite (Sigma-Aldrich), $0.025 \mathrm{mg} / \mathrm{ml}$ insulin (Sigma-Aldrich), $0.1 \mathrm{mg} / \mathrm{ml}$ transferrin (Sigma-Aldrich), and $2 \mu \mathrm{g} / \mathrm{ml}$ heparin (sodium salt, grade II; Sigma-Aldrich), bFGF (human recombinant, $10 \mathrm{ng} / \mathrm{mL}$; Life Technologies) and EGF (human recombinant, $20 \mathrm{ng} / \mathrm{mL}$; Life Technologies). Spheres formed after 5-7days were harvested, collected by centrifugation $(10 \mathrm{~min}$ at $123 \mathrm{~g}$ ), mechanically dissociated to a single-cell suspension, and re-plated in the medium indicated above (Marfia et al., 2011; Gritti et al., 2002; Bottai et al., 2008). As previously described, Er-NPCs differentiation was performed by plating the dissociated stem cells at the density of 40,000 cells $/ \mathrm{cm}^{2}$ in presence of adhesion molecules (Matrigel ${ }^{\mathrm{TM}}$, BD Biosciences, Buccinasco, MI, Italy) and bFGF (10 ng/ml) for 48 hours. After this time, the medium was changed and cells were exposed to the same medium containing foetal bovine serum ( $1 \% \mathrm{vol} / \mathrm{vol}$; Euroclone) and depleted of bFGF. This incubation lasted for the following 5 days (Marfia et al. 2011; Carelli et al. 2014b, Carelli et al. 2015). Then, the extent of 
differentiation was investigated by immunocytochemical staining (Marfia et al., 2011). To monitor the fate of Er-NPCs after transplantation PKH26 and H33342 were used (Sigma-Aldrich). PKH26 is a non toxic cell dye characterized by a long aliphatic tails (PKH26) that allow the dye incorporation in lipid regions of the cell membrane (Horan et al., 1990; Wallace et al., 2008). Er-NPCs were labelled just before the injection, following manufacturer's instructions and as described previously (Carelli et al., 2014a; Liu et al., 2014).

Er-NPCs were stained with Hoechst 33342 (Sigma-Aldrich, Steinheim, Germany) at not toxic concentration $(0.5 \mu \mathrm{g} / \mathrm{mL})$. Floating mechanically dissociated NPCs were incubated with H33342 solution at the final concentration of $0.5 \mu \mathrm{g} / \mathrm{ml}$ for 90 minutes at $37^{\circ} \mathrm{C}$ in an incubator. After staining, the cells were pelleted by centrifugation $(500 \times \mathrm{g}$ for $5 \mathrm{~min})$ and rinsed twice with HBSS (10 ml) (Carelli et al., 2014a). For transplantation labelled cells were resuspended in sterile physiologic solution at a concentration of $3.3 \times 10^{5}$ cells $/ 50 \mu l$ (Carelli et al., 2014a; Carelli et al., 2015).

\subsection{Setting of experimental groups and cell administration}

Experimental animals were divided into three groups: 1) Laminectomies mice $(n=6)$; 2) Lesioned mice treated with phosphate buffer (PBS, $n=15$ ); 3) Lesioned mice transplanted with Er-NPCs $(n=15)$. The traumatic SCI was performed using an Infinite Horizon (IH; Precision Systems and Instrumentation, LLC, Lexington, KY, USA) device (Carelli et al., 2014a; Gorio et al., 2007) at the T8 level. Surgery on the animals was performed as previously described (Carelli et al., 2014a; Carelli et al., 2014b; Carelli et al., 2015; Gorio et al., 2007). Er-NPCs were administered after spinal cord lesion and intravenous administration (i.v.) was performed by tail vein injection. As previously described, the treatment includes three different i.v. injection of $50 \mu l$ in volume, the first administration $30 \mathrm{~min}$ after injury, followed by a second injection $6 \mathrm{~h}$ later and a third one $18 \mathrm{~h}$ after the lesion (Carelli et al., 2014a; Carelli et al., 2014b; Carelli et al., 2015).

\subsection{Behavioural tests and hind limb function}

As described by Basso and co-workers (Basso et al., 2006) functional recovery evaluations were assessed in a blinded fashion. Neurological function was evaluated first $24 \mathrm{~h}$ after injury and then twice a week for the first 4 weeks. The methods utilized are well known in the field of behavioural evaluation of recovery of function after SCI (Basso et al., 2006). For behavioural experiments we used 12 animals for all experimental groups. Allodynia-like responses in the unaffected forepaw were assessed by means of standard hotplate test and cold stimulation as previously reported (Carelli et al., 2014b; Carelli et al., 2015; Hofstetter et al., 2005).

\subsection{Histology and immunohistochemistry}

At the end of the experimental period, animals were anesthetized and perfused as described previously [11-13]. Spinal cords were post-fixed overnight, cryoprotected with $30 \%$ sucrose (Sigma-Aldrich), quickly frozen, stored at $-80^{\circ} \mathrm{C}$ and sectioned by means of a cryostat (Leica) (Carelli et al. 2014a; Carelli et al., 2014b; Carelli et al., 2015). Cryostat sections $(15 \mu \mathrm{m})$ were collected onto glass slides and processed for immunohistochemistry. Sections were rinsed with PBS (Euroclone), treated with blocking solution (Life-Technologies) and incubated with primary antibodies overnight at $4{ }^{\circ} \mathrm{C}$. After treatment with primary antibodies, the sections were washed with PBS and incubated with appropriate secondary antibodies (Alexa Fluor ${ }^{\circledR}$ 488, Molecular Probes ${ }^{\circledR}$, Life Technologies) for 2 hours at room temperature. Sections were washed in PBS, nuclei were stained with DAPI $(1 \mu \mathrm{g} / \mathrm{ml}$ final concentration, 10 minutes at room temperature; Sigma-Aldrich) and then mounted using the FluorSave Reagent (Calbiochem, Merck Chemical, Darmstadt, Germany) and analyzed by confocal microscopy. In control determinations, primary antibodies were omitted and replaced with equivalent concentrations of unrelated IgG of the same subclass. The following primary antibodies were used:, $\beta$-Tubulin III (1:150; Covance). Microtubule-Associated Protein 2 (MAP-2; 1:300; Chemicon), Tyrosine hydroxylase (TH; 1:500; Millipore), Choline Acetyltransferase (ChAT; 1:1000; Chemicon), 5-hydroxytryptamine (5-HT; 1:200 Millipore); GAP-43 (1:1000; Millipore).

\subsection{Assessment of myelin preservation}

Assessment of myelin preservation was evaluated on cord sections of non- lesioned (healthy), lesioned + PBS and lesioned + Er-NPCs animals placed on the same coverslip as described previously (Pertici 
et al., 2013; Carelli et al., 2014b; Carelli et al., 2015). This approach allows for the homogeneous evaluation of quantitative data obtained by confocal analysis. Myelin preservation was evaluated comparing the levels of myelin in the ventral white matter at $0.4 \mathrm{~mm}$ (rostral and caudal) laterally from the lesion epicenter in healthy, saline and cells treated animals. The choice of the ventral white matter was based on the knowledge that the reticular spinal pathway descends mostly in the ipsilateral dorsoand ventrolateral funiculi and is directly involved in the regulation of the movement of the mouse foot (Vitellaro-Zuccarello et al., 2007). The confocal microscope images for the laminectomies animals and saline and cells-treated mice were obtained using the same intensity, pinhole, wavelength and thickness of the acquisition. As reference, we used sections close to the ones analyzed and not treated with fluoromyelin (Pertici et al., 2013; Carelli et al., 2014b; Carelli et al., 2015). Briefly, the procedure of the staining was carried out by incubating the cryosections with fluoromyelin diluted 1:300 in PBS for 20 minutes; slides were then washed three times for $10 \mathrm{~min}$ each with PBS and mounted with FluorSave (Merck, Darmstadt, Germany), and qualitatively and quantitatively analyzed by confocal microscopy (Leica TSC2; Leica Microsystems, Heidelberg, Germany).

\subsection{Fluoro-Ruby Protocol}

Fluororuby is a fluorescent rhodamine-conjugated dextran, which has been used to study in vivo axonal transport within the central nervous system (Lu et al., 2001). A $10 \%$ solution of Fluororuby is made by dissolving $10 \mathrm{mg}$ of dry powder in $100 \mu \mathrm{L}$ of PBS, that was delivered via intraspinal injection at $\mathrm{T} 6 / \mathrm{T} 7 \mathrm{using}$ a $5 \mu \mathrm{L}$ Hamilton microsyringe. Injection volumes typically ranged from $0.5-1 \mu \mathrm{L}$ and were gradually injected over a 10-15 minute interval (Schofield et al., 2007). The animals were then allowed to recover. The animals were perfused 5 days after the tracer injection with neutral buffered formaldehyde $(10 \%$ formalin in $0.1 \mathrm{M}$ neutral phosphate buffer). The spinal cord was then removed, and post-fixed for at least overnight in the same fixative solution and included in paraffin. The cords were then sectioned by means of a microtome (Zeiss) with thickness set at 10 microns. This analysis was performed on 3 animals per experimental group: (i) injected with saline solution as a control and (ii) Er-NPCs-transplanted animals.

\subsection{Semiquantitative method of analysis for the determination of serotoninergic and catecholaminergic fiber density}

Data were collected from sections taken at the same distance $(2 \mathrm{~mm})$ from the lesion epicenter and immunostained in a single batch to minimize variability. Images were acquired using standardized confocal microscopy (Hawthorne et al., 2011; Shigyo et al., 2016). Five consecutive sections ( $10 \mu \mathrm{m}$ thick) were averaged, and the count was serially repeated every $50 \mu \mathrm{m}$ for the length of $500 \mu \mathrm{m}$. Semiquantitative analysis of immunoreactivity was performed by using confocal microscopy (Leica SP2 confocal microscope with $\mathrm{He} / \mathrm{Kr}$ and Ar lasers; Heidelberg, Germany) to evaluate the mean relative optical density. Quantification of serotonin (5-HT) and tyrosin hydroxilase (TH) immunoreactivity was carried out in the regions reported in Figs. 4 and 5 following the procedure described for myelin assessment.

\subsection{Statistical analysis}

Data were expressed as the mean \pm S.D. Multiple groups comparison were made by ANOVA followed by Bonferroni's multiple comparisons test to assess statistical significance versus respective control. The analyses were performed using Prism 3.0 software (GraphPad Software, Inc.). Statistical significance was accepted for a $P<0.05$.

\section{Results}

\subsection{Er-NPCs elicit neuronal markers expression in recipient spinal cord}

Transplanted Er-NPCs localize at the edges of injury site and show a well-structured morphology with dendrite-like processes; they are mostly positive for Choline-AcetylTransferase (ChAT) (Carelli et al., 2015 and Fig. 1). The quantification performed 30 days after transplantation shows that $75 \pm 5.35$ percent of transplanted Er-NPCs (PKH26 positive cells) are positive for ChAT, with a dotted (Fig. 1) distribution that in most cases is perinuclear, with positive labeling of processes in several instances (Fig. 1). The high majority of Er-NPCs localized at the boundaries of lesion site are also positive for MAP-2 and $\beta$-tubulin III (Fig. 2). As reported in our previous work also in this new set of experiments none of engrafted Er-NPCs resulted positive to GFAP or 


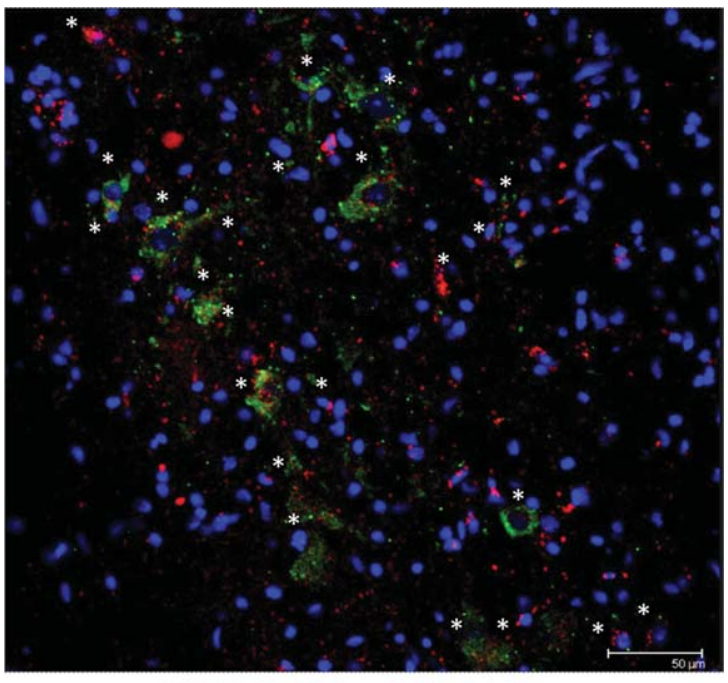

PKH26 Er-NPCs; ChAT; DAPI

Fig. 1. Er-NPCs transplanted cells differentiate into cholinergic neurons. At 30 days after i.v. injection, several PKH26-labeled Er-NPCs (red) were accumulated at the edges of the lesion. Most Er-NPCs were positive for ChAT immunostaining (green; stars) $($ Scale bar $=50 \mu \mathrm{m})$.

oligodendrocyte markers (Carelli et al., 2015). The quantification of MAP-2 and $\beta$-tubulin III labelling in the cord of treated animals had been performed in sections taken both at lesion site and distally $(2 \mathrm{~mm}$ rostral and caudal, respectively; schematic in Fig. 2). The presence of transplanted Er-NPCs enhances tissue expression of these typical neuronal markers at the lesion site and the rostral and caudal peripheries (Fig. 2).

The evaluation of hind limb function recovery performed by open field locomotion test is reported in Fig. 3. The experimental animals, tested the day prior to the injury, scored the maximum (9 points) in the BMS scale. The 70 Kdyne traumatic impact to the mouse cord causes a transient loss of locomotion ability, that is followed by a progressive gradual recovery reaching the maximum extent within 2-3 weeks ( $3.0 \pm 0.450$ points of the BMS scale; $n=6$, Fig. 3) (Carelli et al., 2014a; Carelli et al., 2014b; Carelli et al., 2015). This score corresponds to plantar placing of the paw with or without weight support (Basso et al., 2006). When Er-NPCs were infused by i.v. injection (Carelli et al., 2014a) the outcome improved and reached a BMS score of $5.0 \pm 0.50$ at day $30(n=6)$ (Basso et al., 2006). This corresponds to frequent or consistent plantar stepping without coordination, or frequent or consistent plantar stepping with some coordination (Basso et al., 2006; Carelli et al., 2014a; Carelli et al., 2014b; Carelli et al., 2015). The cell-mediated improvement is particularly evident during the first 3 weeks after SCI, and then the recovery improved steadily up to 90 days of observation (Tables 1 and 2). Two cords of treated mice at 12 weeks after Er-NPCs administration were serially sectioned and the number of PKH26 or Hoechst positive cells per cord was quantified as previously described (Carelli et al., 2015). The total number of positive cells was $22,31 \times 10^{5} \pm 6,7 \times 10^{5}$ per cord at 12 weeks after transplantation. This is in complete accordance with previously reported data (Carelli et al., 2015), and the estimate was 10 fold higher than survival of regular adult NSCs (Bottai et al., 2008).

\subsection{Monoaminergic fibers in the injured cord}

Serotonin (5-HT) innervation of the cord is involved in the regulation of the central pattern generator and the facilitation of locomotion (Lemon, 2008; Liu et al., 2009; Han et al., 2015) thus 5-HT immunoreactivity was investigated in the injured cord of untreated or Er-NPCs treated animals. Positive 5HT staining was detected in the lesion center and in regions $2 \mathrm{~mm}$ rostral and caudal to the lesion center (Fig. 4). Representative 5-HT immunoreactivity is shown in the lesion epicenter, in its boundaries (Fig. 4 panel A), and distally ( $2 \mathrm{~mm}$ rostral or caudal to the lesion site; Fig. 4 panel B). 5-HT positive fibers (green) form a reach network also caudally to the lesion site in Er-NPCs-treated animals. The quantification performed at 10 and 30 days after lesioning in the caudal cord, shows that the loss of 5-HT fibers is $60-70 \%$; this remains unchanged at 10 days after transplantation (Fig. 4 panel C). However, later at 30 days, 5-HT fibers are markedly more abundant both in the ventral horns and in the intermediolateral area (Fig. 4 panel C). A similar outcome has been observed with TH-positive fiber; a sharp decrease is followed by a significant recovery of TH-positive fibers innervation in the caudal cord (Fig. 5 panels B and C). In saline-treated mice, there is no recovery of 5-HT and TH positive fibers (Figs. 4 and 5). These data suggest that transplanted Er-NPCs have favored the recovery of 5-HT and catecholaminergic fiber tracts of the lesioned cord even in the caudal region and across the lesion site.

\subsection{Myelin preservation}

The reticulospinal tract is an important pathway for the control of locomotion through the coordination of 
A

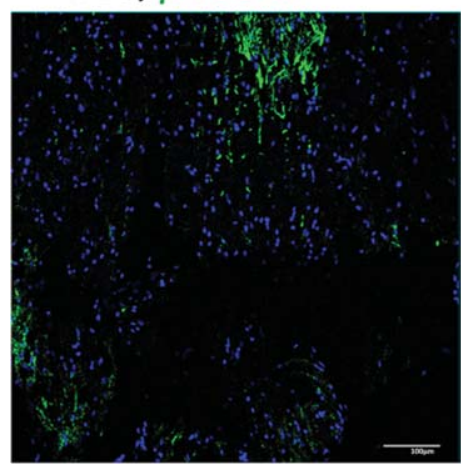

PBS; MAP-2

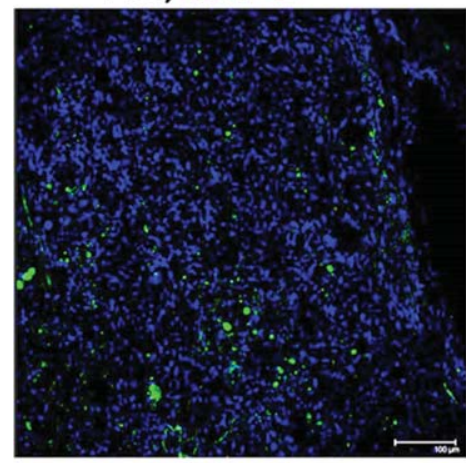

PKH26 Er-NPCs; $\beta$ TUB III

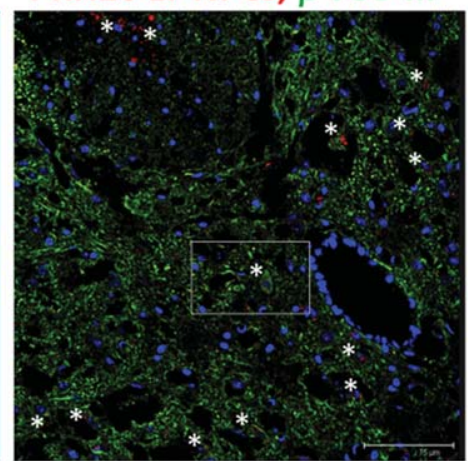

PKH26 Er-NPCs; MAP-2

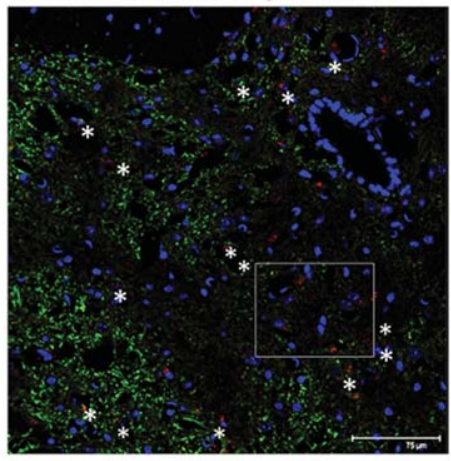

MAP-2 quantification

B

$\beta$-TUB III quantification

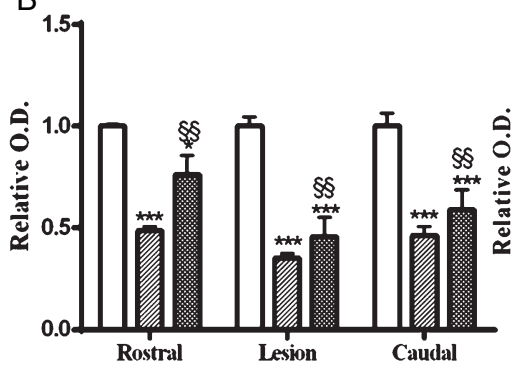

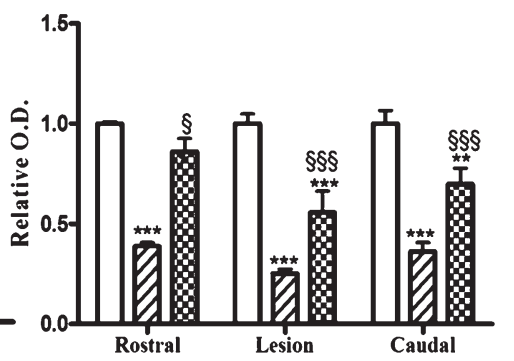
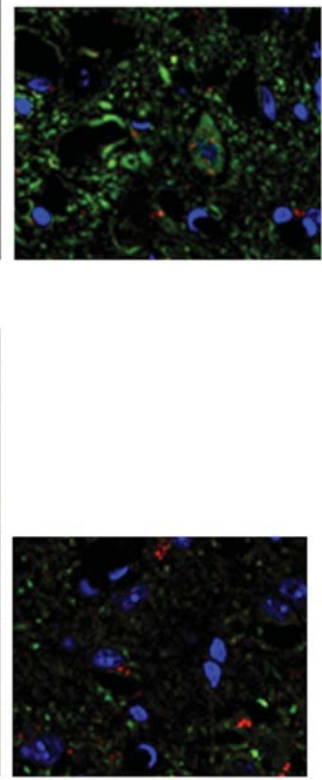

$\square$ LAM

DI LES+PBS

LES+Er-NPCs

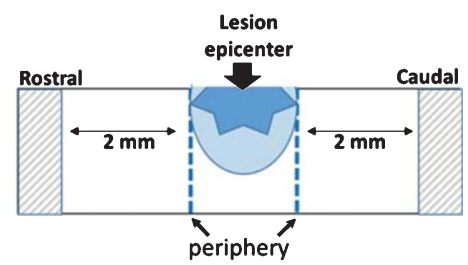

Fig. 2. Er-NPCs transplantation improves neural markers expression in injured spinal cord. Pictures represent confocal acquisitions of coronal sections taken at the edges of the lesion at 30 days after i.v. administration of PKH26 - labeled Er-NPCs (showed in red) (panel A). Sections were immunostained for $\beta$ tubulin III and MAP-2 (showed in green). PKH26-labeled cells were positive for $\beta$-tubulin III and MAP-2 (white stars) (Scale bar $=75$ and $100 \mu \mathrm{m}$ ) (panel A). Graphs reported in panel B show the quantification of immunoreactivity in sections taken at the lesion epicenter, $2 \mathrm{~mm}$ rostral or caudal to the lesion epicenter (please see schematic representation). Values represent average $\pm \mathrm{SD}$. We determined the statistical differences by means of ANOVA test followed by Bonferroni's post-test. *** $p<0.001 \mathrm{vs} \mathrm{LAM}$; $\$ \$ p<0.01$ vs PBS.

rhythmic stepping movements (Ballerman \& Fouad, 2006). It runs in the ipsilateral dorso- and ventrolateral funiculi of the cord, and is predominantly constituted by myelinated axons (Loy et al., 2002). The extent of myelination of these pathways depends marginally on the presence of serotonergic axons in these bundles since they are scarcely myelinated (Loy et al., 2002; Hildebrand \& Hahn, 1978). The condition of myelin in these descending structures was determined by evaluation of FluoroMyelin ${ }^{\mathrm{TM}}$ staining by means of confocal quantitative analysis as detailed in Materials and Methods. Myelin was quantified 30 days after lesion; sections were taken at the center of the lesion and $2 \mathrm{~mm}$ caudally to the lesion site (Fig. 6). Only intact myelin was assessed, and the degenerated crumbled labeled parts were not 


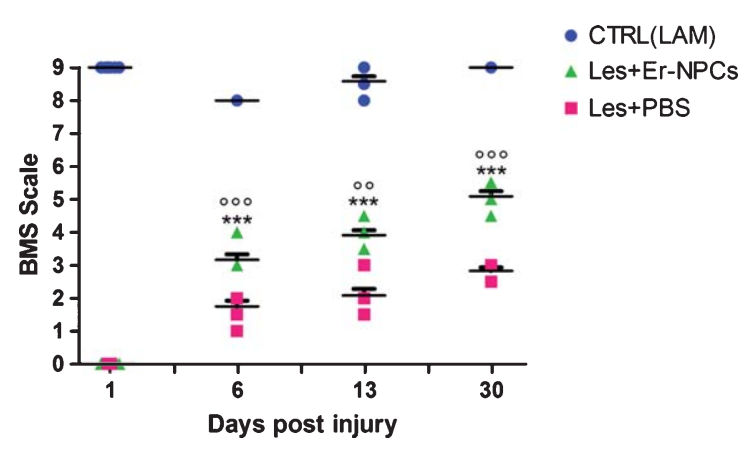

Fig. 3. Mice locomotor activity evaluation after i.v. Er-NPCs infusion. The evaluation of motor function recovery of hind limb was determined by the open field locomotion test (Basso et al., 2006). During the observation, performed in double blind fashion, animals from the different groups were randomized. Values represent average \pm SD. We determined the statistical differences by means of two way ANOVA test followed by Bonferroni's post-test.

\section{Table 1}

Mice locomotor activity evaluation after i.v. Er-NPCs injection. Functional recovery of hind limb was determined by the open field locomotion test (Basso et al., 2006; see Materials and Methods for details). Values represent average $\pm S D$. We determined the statistical differences by means of two way ANOVA test followed by Bonferroni's post-test

\begin{tabular}{lllc}
\hline Days & LAM & \multicolumn{1}{c}{ PBS } & Er-NPCs \\
\hline-1 & $9.0 \pm 0$ & $9.0 \pm 0$ & $9.0 \pm 0$ \\
1 & $8.0 \pm 0.05$ & $0.0 \pm 0.87$ & $0.0 \pm 0.10$ \\
6 & $8.5 \pm 0.05$ & $2.0 \pm 0.230$ & $3.0 \pm 0.20$ \\
& & & $(p<0.01$ vs PBS $)$ \\
13 & $8.5 \pm 0.13$ & $2.5 \pm 0.140$ & $3.5 \pm 0.30$ \\
& & & $(p<0.001$ vs PBS $)$ \\
18 & $9.0 \pm 0.06$ & $2.5 \pm 0.130$ & $4.0 \pm 0.30$ \\
& & & $(p<0.001$ vs PBS $)$ \\
24 & $9.0 \pm 0.06$ & $3.0 \pm 0.220$ & $4.5 \pm 0.45$ \\
& & & $(p<0.001$ vs PBS $)$ \\
30 & $9.0 \pm 0.06$ & $3.0 \pm 0.170$ & $5.0 \pm 0.35$ \\
& & & $(p<0.001$ vs PBS $)$ \\
90 & $9.0 \pm 0.06$ & $3.0 \pm 0.280$ & $5.5 \pm 0.45$ \\
& & & $(p<0.001$ vs PBS $)$ \\
\hline
\end{tabular}

considered. The loss of myelin was evident at lesion site and caudally, the transplanted Er-NPCs markedly improved the extent of myelination at all analyzed sites (Table 3).

Growth-associated protein 43 (GAP43) is expressed at higher levels in neuronal growth cones during development, during axonal regeneration and it is an accepted marker of neurite outgrowth (Meiri et al., 1986; Skene et al., 1986; Verkade et al., 1996). To corroborate the above-described evidences on Er-NPCs mediated re-growth of monoaminergic pathways, spinal cord cryostat sections, taken at $2 \mathrm{~mm}$ from lesion epicenter, were examined for GAP43 expression at 30 days after cells administration
Table 2

Prospective analysis (time) of functional recovery promoted by ErNPCs. Hind limb functional recovery of function was evaluated by the open field locomotion test (Basso et al., 2006; see Materials and Methods for details). Values represent average \pm SD. Statistical significance was determined by applying two way ANOVA test followed by Bonferroni's post-test

\begin{tabular}{lcc}
\hline $\begin{array}{l}\text { Days post } \\
\text { Er-NPCs infusion }\end{array}$ & $\begin{array}{c}\text { Behaviour } \\
\text { (BMS scale) }\end{array}$ & $P$ value \\
\hline 1 & $0.0 \pm 0.10$ & \\
6 & $3.0 \pm 0.20$ & $p<0.001$ vs day 1 \\
13 & $3.5 \pm 0.30$ & $p<0.001$ vs day 1 \\
& $p=$ n.s. vs day 6 \\
30 & $5.0 \pm 0.35$ & $p<0.001$ vs day 1 \\
& & $p<0.001$ vs day 6 \\
& & $p<0.01$ vs day 13 \\
90 & $5.5 \pm 0.45$ & $p<0.001$ vs day 1 \\
& & $p<0.001$ vs day 6 \\
& & $p<0.01$ vs day 13 \\
& & $p=$ n.s. vs day 30 \\
\hline
\end{tabular}

(Fig. 7). The immunoreactivity for GAP-43 was especially noticeable in bundles positive to $\beta$-tubulin III and in proximity of Er-NPCs (labelled with Hoechst). The quantification of $\beta$-Tubulin III positive cells expressing GAP43 was performed. The graph reported in Fig. 7 shows a significant increase in transplanted animals both rostrally and caudally to the lesion epicenter.

\subsection{Fluororuby-labeled axonal regeneration in the injured cord}

To evaluate quantitatively anterograde axonal regeneration fluoro-ruby was injected in the rostral cord at T6/T7 level five and twenty days after injury (Materials \& Methods section for details; Fig. 6) (Erturk et al., 2012). Then, animals were sacrificed five days after tracer injection. At the earliest time point (10 days after injury and cells administration), we observed that, while the tracer was being injected, it quickly filled the cord and diffused rapidly away from injection site, probably dissolved in the fluids of the trauma-induced edema. The tracer distribution in the cord was rather homogenous and at the lesion site, the cord was filled completely up to the meninges (data not shown). Differently, at 25 days post injury and Er-NPCs transplantation, fluoro-ruby remained at site of injection with a negligible diffusion and was picked up by intact axons. Thus labelling occurred from the injection site to the caudal cord across the lesion, this occurred both in saline and cells-treated animals (Fig. 8). The dorsal tract labeling is highest at the point of injection, and then it gradually decreases moving from the site of injection 


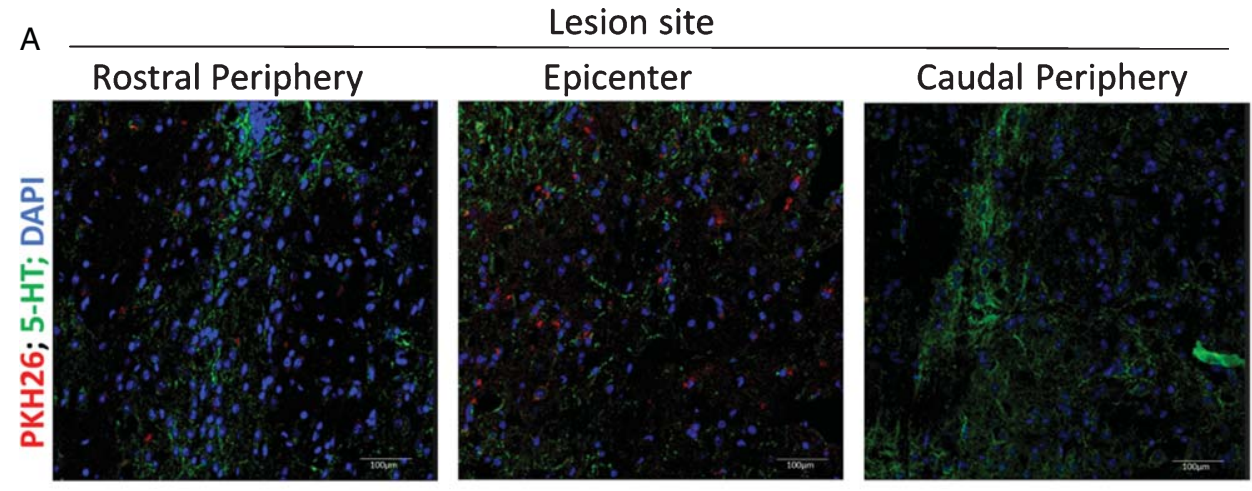

B
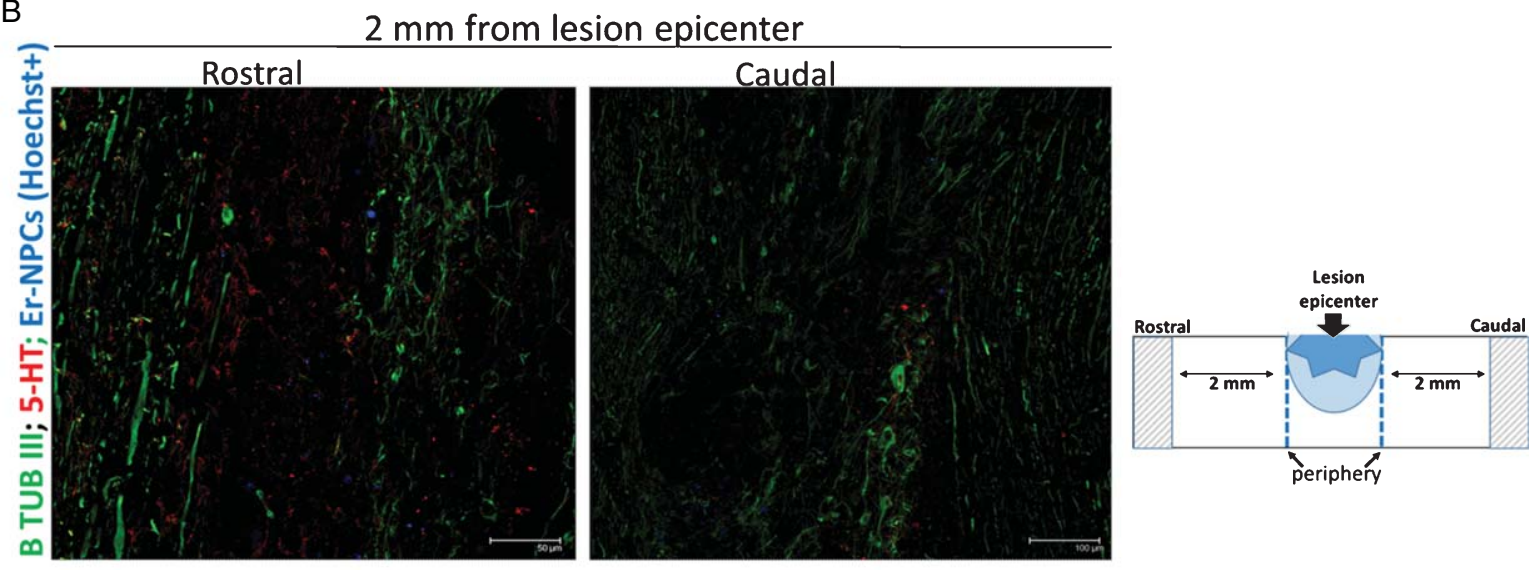

C

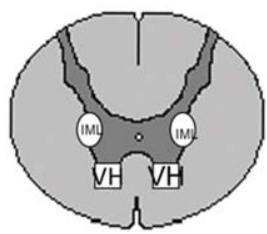

$\mathrm{VH}=$ ventral horn;

$\mathrm{IML}=$ intermediolateral
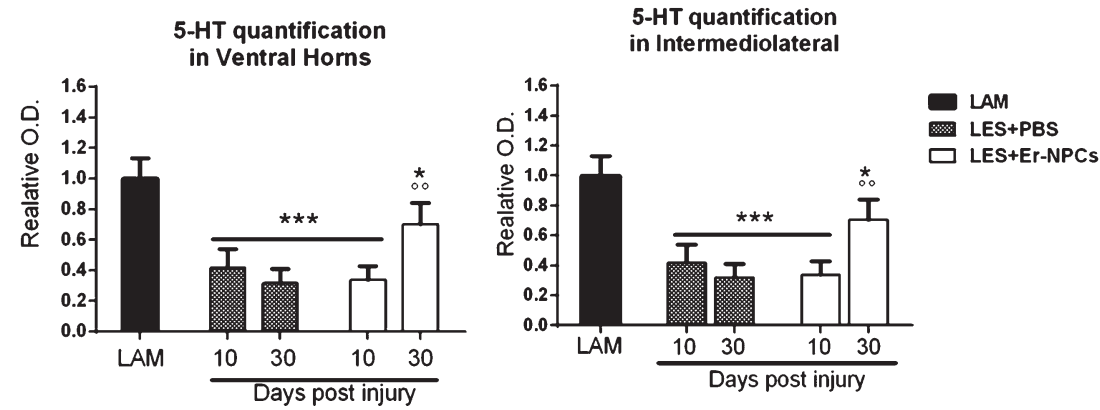

Fig. 4. Er-NPCs promote serotoninergic fibres sprouting through the lesion site. Serotoninergic (5-HT) fibers were investigated at the lesion site (panel A) and $2 \mathrm{~mm}$ away from the lesion (panel B) 4 weeks after Er-NPCs infusion in lesioned mice. In panel A, Er-NPCs are shown in red (PKH26) and 5-HT is shown in green. Nuclei were counterstained with DAPI (blue). In panel B, 5-HT staining is showed in red and neuronal fibers were identified with beta-tubulin III (green). Er-NPCs were labelled with Hoechst 33342 before the infusion (blue). Scale bars $=50$ and $100 \mu \mathrm{m}$. Quantification was performed $2 \mathrm{~mm}$ caudally to the lesion epicenter at 10 and 30 days after Er-NPCs transplantation in lesioned animals (panel C). The quantification was performed in spinal cord coronal sections $(n=3$ for each animal; at least 6 animal per group) as described in detail in M\&M in intermediolateral and ventral horns (please see the representation). Values represent average \pm SD. We determined the statistical differences by means of an ANOVA test followed by Bonferroni's post-test. $* * * p<0.001 \mathrm{vs} \mathrm{LAM} ;{ }^{\circ} p<0.05$ vs LES+PBS.

to the lesion site and it is very limited in the caudal cord of saline-treated mice (Fig. 8 panel A). Such a labelling is, however, much higher in the Er-NPCs transplanted animals (Fig. 8 panel A). The highest number of labelled axons is localized in the rostral region of the lesion, but, as expected, they accumulate at the injury boundaries where transplanted cells are located. Several of these axons cross the lesion and their number increases again just caudal to the lesion as axons likely sprout when entering the denervated caudal cord. The quantification of fluoro-ruby labelled axons is reported in panel $\mathrm{C}$ of the same 


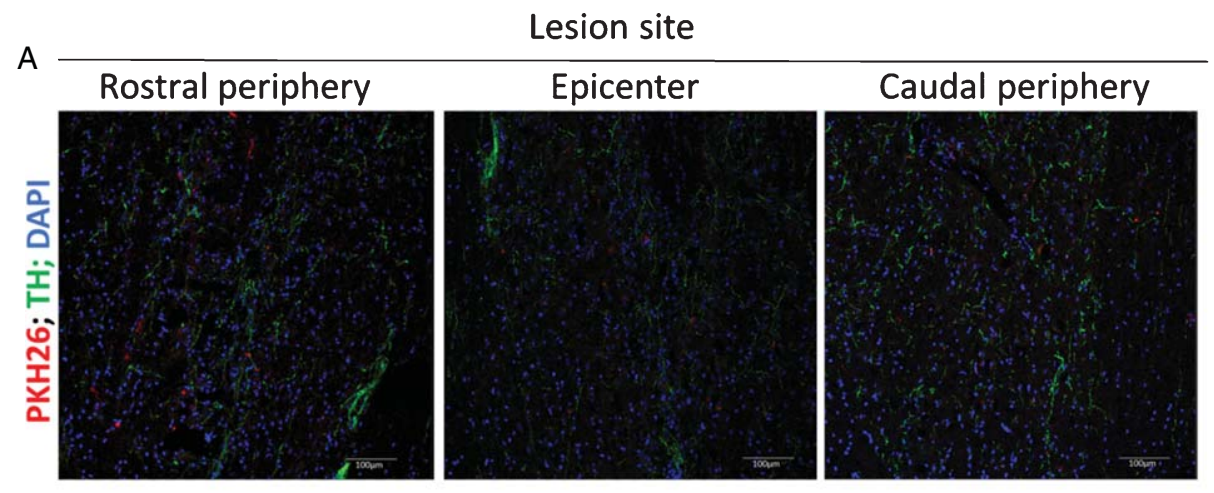

B
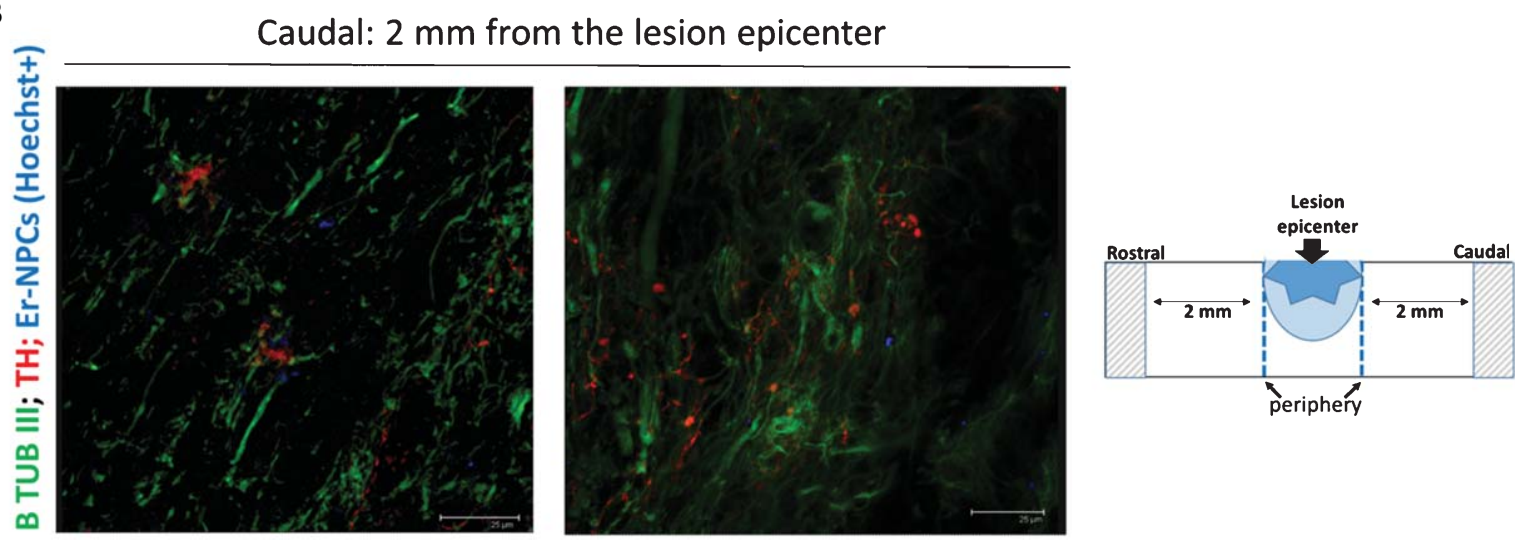

C

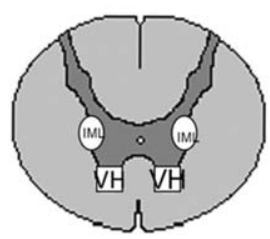

$\mathrm{VH}=$ ventral horn; IML= intermediolateral
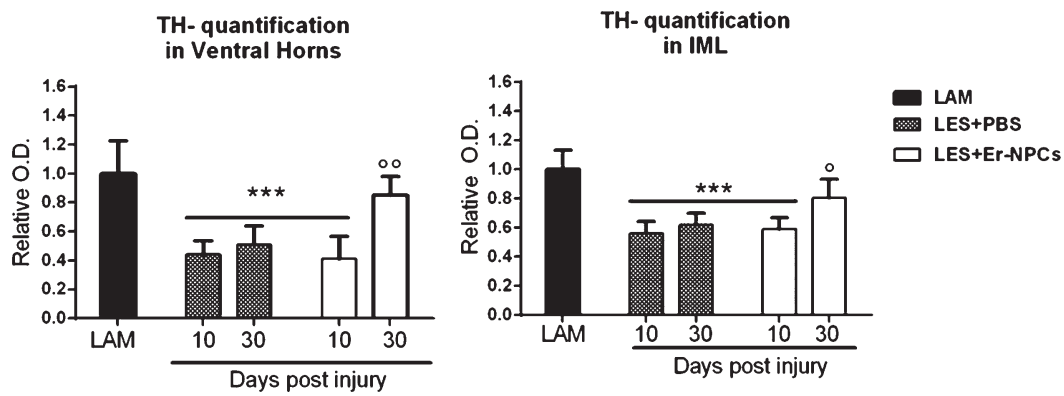

Fig. 5. Er-NPCs promote chatecolaminergic fibres sprouting through the lesion site. Chatecolaminergic (TH) fibers were investigated at the lesion site (panel A) and $2 \mathrm{~mm}$ caudal from the lesion (panel B) 4 weeks after Er-NPCs infusion in lesioned mice. In panel A, Er-NPCs are shown in red and TH is shown in green. Nuclei were counterstained with DAPI (blue). In panel B, chatecolaminergic terminals are shown in red and neuronal fibers were identified with beta-tubulin III (green). Er-NPCs were labelled with Hoechst 33342 before the infusion (blue). Scale bars $=25 \mu \mathrm{m}$. Quantification of TH fibers quantification was performed $2 \mathrm{~mm}$ caudally to the lesion epicenter at 10 and 30 days after Er-NPCs transplantation in lesioned animals. The quantification was performed in spinal cord coronal sections $(n=3$ for each animal; at least 6 animals per group) as described in detail in M\&M in intermediolateral and ventral horns (please see the representation). Values represent average \pm SD. We determined the statistical differences by means of an ANOVA test followed by Bonferroni's post-test. $* * * p<0.001 \mathrm{vs}$ LAM; ${ }^{\circ 0} p<0.01$ vs LES+PBS.

figure and shows a ten-fold increase of axon labeling in the caudal cord proximal to the lesion $(1 \mathrm{~mm})$ of ErNPCs-treated animals (Fig. 8). The labeling details in the lesion epicenter are shown in Fig. 9. The higher axonal labeling observed in the rostral regions suggests a powerful axonal regeneration promoted by Er-NPCs localized at the injury site (Figs. 8 and 9).

\section{Discussion}

The results described in this study extend previous observations on the reparatory properties of Er-NPCs when applied in spinal cord injury (Carelli et al., 2014b; Carelli et al., 2015). We had reported that i.v. applied Er-NPCs accumulate, survive and 

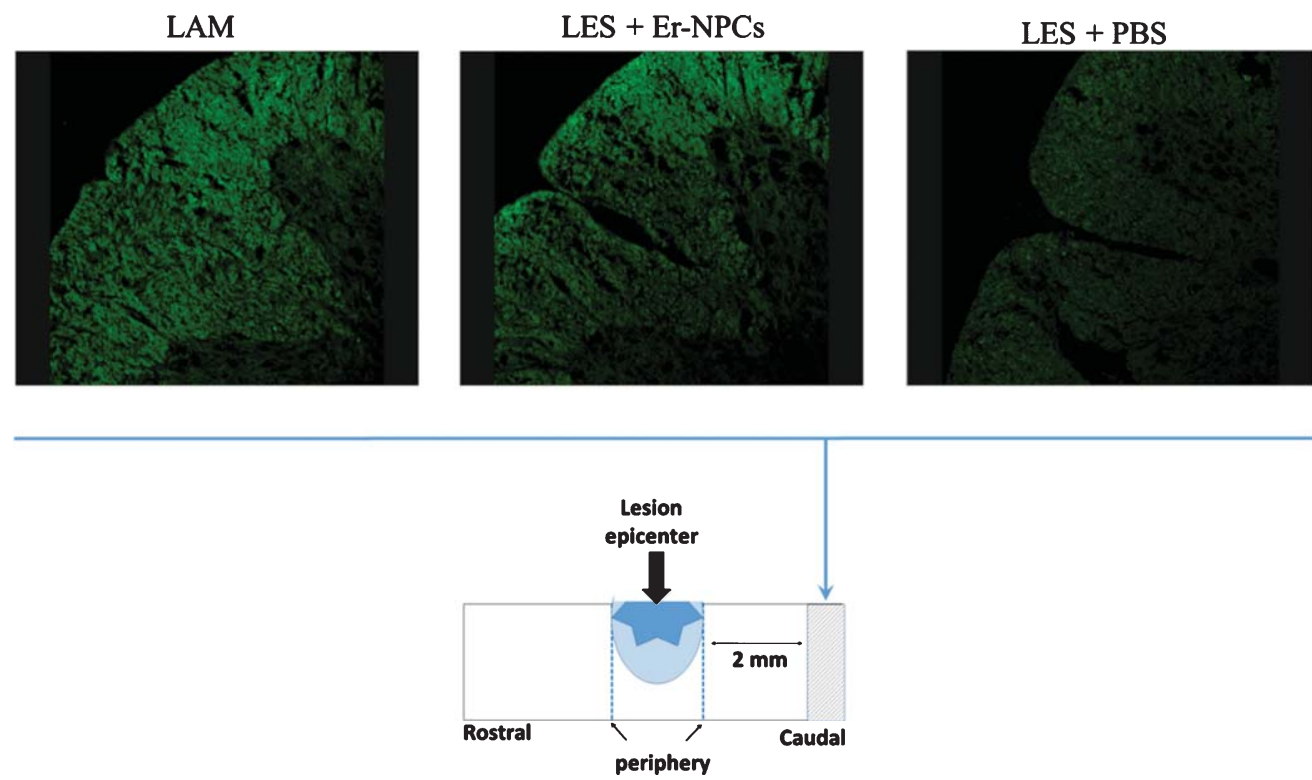

Fig. 6. Myelin preservation in the injured cord of animals treated with Er-NPCs. Myelin preservation was evaluated by means of Fluoromyelin ${ }^{\mathrm{TM}}$ staining (green) performed in sections at the lesion epicenter, and $2 \mathrm{~mm}$ caudally to the lesion site (please see schematic representation).

Table 3

Er-NPCs treatment preserves myelin in the injured cord. Myelin preservation was evaluated by means of Fluoromyelin ${ }^{\mathrm{TM}}$ staining (green) performed in sections at the lesion epicenter, and $2 \mathrm{~mm}$ caudally to the lesion site (please see Supplementary Figure 2). Quantification was performed by confocal analysis of ventral and lateral white matter sections taken as indicated in the graphs. For the quantification, we considered sections $(n=3)$ from three animals per group. Values represent average \pm SD. We determined the statistical differences by means of ANOVA test followed by Tukey's post-test

\begin{tabular}{|c|c|c|c|c|}
\hline & \multicolumn{2}{|c|}{ Lesion site } & \multicolumn{2}{|c|}{$2 \mathrm{~mm}$ caudal } \\
\hline & vWM & iWM & vWM & iWM \\
\hline LAM & $1.023 \pm 0.051$ & $1.043 \pm 0.048$ & $1.036 \pm 0.236$ & $1.032 \pm 0.235$ \\
\hline LES+PBS & $\begin{array}{c}0.068 \pm 0.032 \\
(p<0.01 \text { vs LAM })\end{array}$ & $\begin{array}{c}0.495 \pm 0.086 \\
(p<0.01 \text { vs LAM })\end{array}$ & $\begin{array}{c}0.586 \pm 0.041 \\
(p<0.01 \text { vs LAM })\end{array}$ & $\begin{array}{c}0.505 \pm 0.042 \\
(p<0.01 \text { vs LAM } \\
p<0.05 \text { vs PBS })\end{array}$ \\
\hline LES+Er-NPCs & $\begin{array}{c}0.885 \pm 0.251 \\
(p<0.05 \text { vs PBS })\end{array}$ & $\begin{array}{c}0.797 \pm 0.201 \\
(p<0.05 \text { vs PBS })\end{array}$ & $\begin{array}{c}0.737 \pm 0.075 \\
(p<0.01 \text { vs LAM })\end{array}$ & $\begin{array}{c}0.664 \pm 0.068 \\
(p<0.01 \text { vs LAM })\end{array}$ \\
\hline
\end{tabular}

differentiate at injury site and improve recovery of function through the reduction of post-traumatic neuroinflammation (Carelli et al., 2014a; Carelli et al., 2014b; Carelli et al., 2015). Er-NPCs localize at the edges of injury where the microenvironment might be positively affected by the powerful counteraction of reactive inflammation (Carelli et al., 2014b; Carelli et al., 2015). This is accompanied by the significant preservation of lesion site spinal cord parenchyma and significantly attenuated myelin loss in the ventral and medioventral pathways. Here it is shown that such an improvement of the injury site may have changed the cord local microenvironment now capable of sustaining axonal regeneration across the injury as demonstrated by red ruby axonal labelling.
This is also specifically true for descending 5-HT and catecholamine containing fibers that markedly re-innervate the caudal cord. GAP-43 expression is often correlated with axon re-growth potential (Aigner et al., 1995; Benowitz and Routtemberg, 1997; Chaisuksunt et al., 2000; Donnelly et al., 2013), and its higher expression in the caudal cord supports the enhanced regeneration across the lesion in Er-NPCs transplanted mice.

We previously reported that Er-NPCs release erythropoietin (Marfia et al., 2011), and their intrastriatal injection promoted recovery of function in a model of Parkinson's disease through erythropoietin release (Carelli et al., 2016; Carelli et al., 2017). After i.v. infusion Er-NPCs were able to counteract the 


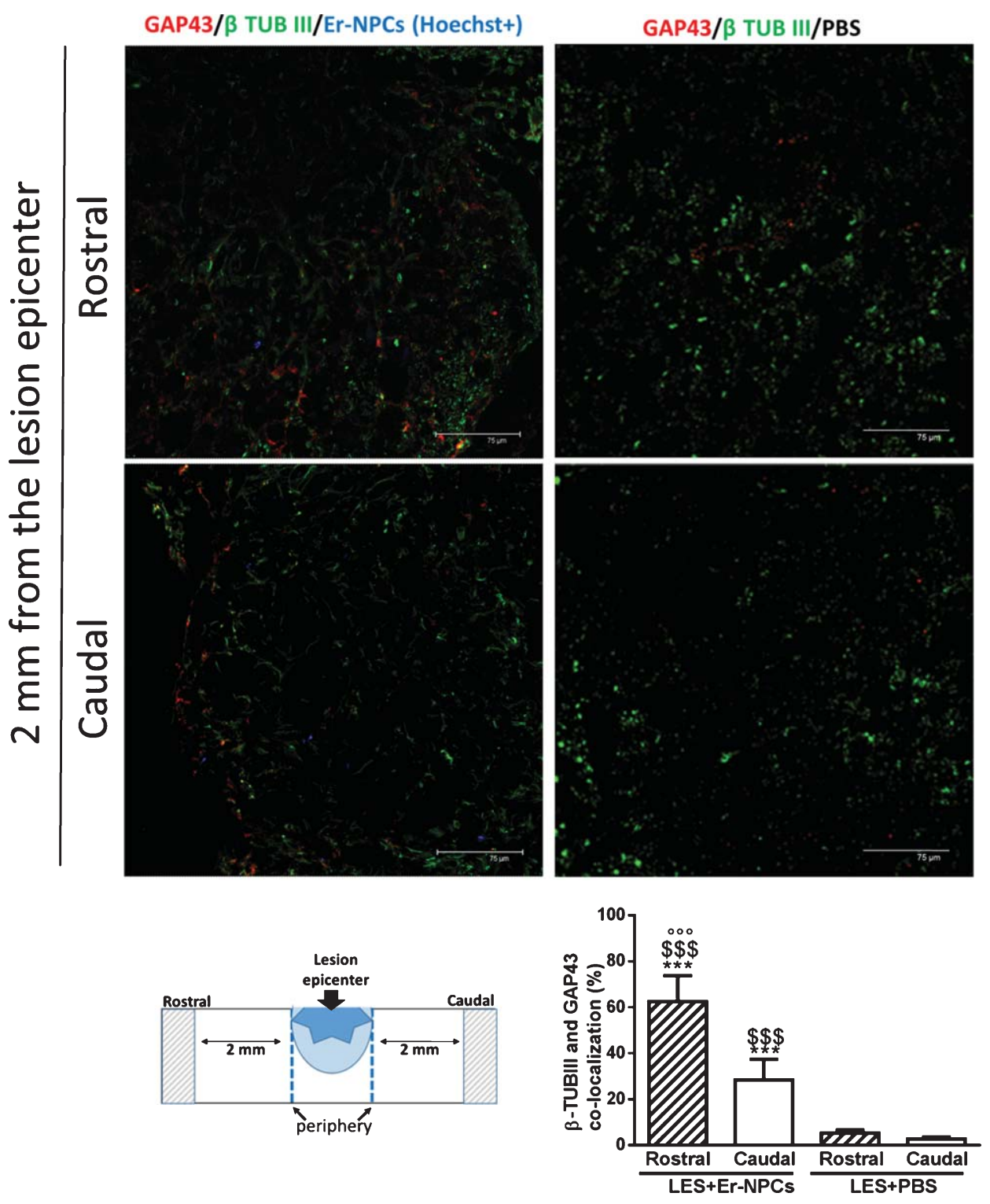

Fig. 7. GAP43 expression in Er-NPCS transplanted cord. Qualitative picture of GAP43 expression investigated 2 mm away (rostral and caudal) from the cord lesion site of lesioned animals transplanted with Er-NPCs and PBS. GAP 43 is showed in red and neuronal fibres were detected with beta-tubulin III staining (green). In order to perform double staining in these experiments Er-NPCs were labelled with Hoechst 33342 (blue). Scale bars $=75 \mu \mathrm{m}$. Pictures are representative of at least three different immunostaining experiments. The fluorescence intensity of GAP 43 is showed in the graph (below) and was performed in three animals per group. Statistical significance was determined by ANOVA test followed by Bonferroni's post-test. $* * * p<0.001$ vs Les+Er-NPCs; ${ }^{\circ 0} p<0.001$ vs Les+PBS rostral; $\$ \$ \$ p<0.001$ vs Les+PBS caudal.

secondary degeneration process by inhibiting the expression of pro-inflammatory cytokines (Carelli et al., 2014b; Carelli et al., 2015). Here, we show that the neuroprotective action of transplanted Er-NPCs allowed the structural preservation or neo-formation of a favorable milieu, this is suggested by the higher preservation of neuronal markers such as $\beta$-tubulin III and MAP-2 at the lesion site. This is in agreement with previously reported reduction of the lesion size by Er-NPCs administration as shown by quantitative morphology and in vivo NMR (Carelli et al., 2015). Our lesioning paradigm does not completely severe the cord, and in addition to the lateral and ventral pathways there are channels of survived spinal tissue, but the post-traumatic inflammation and hypoxia renders these portions quite hostile for axonal regrowth. It is, 


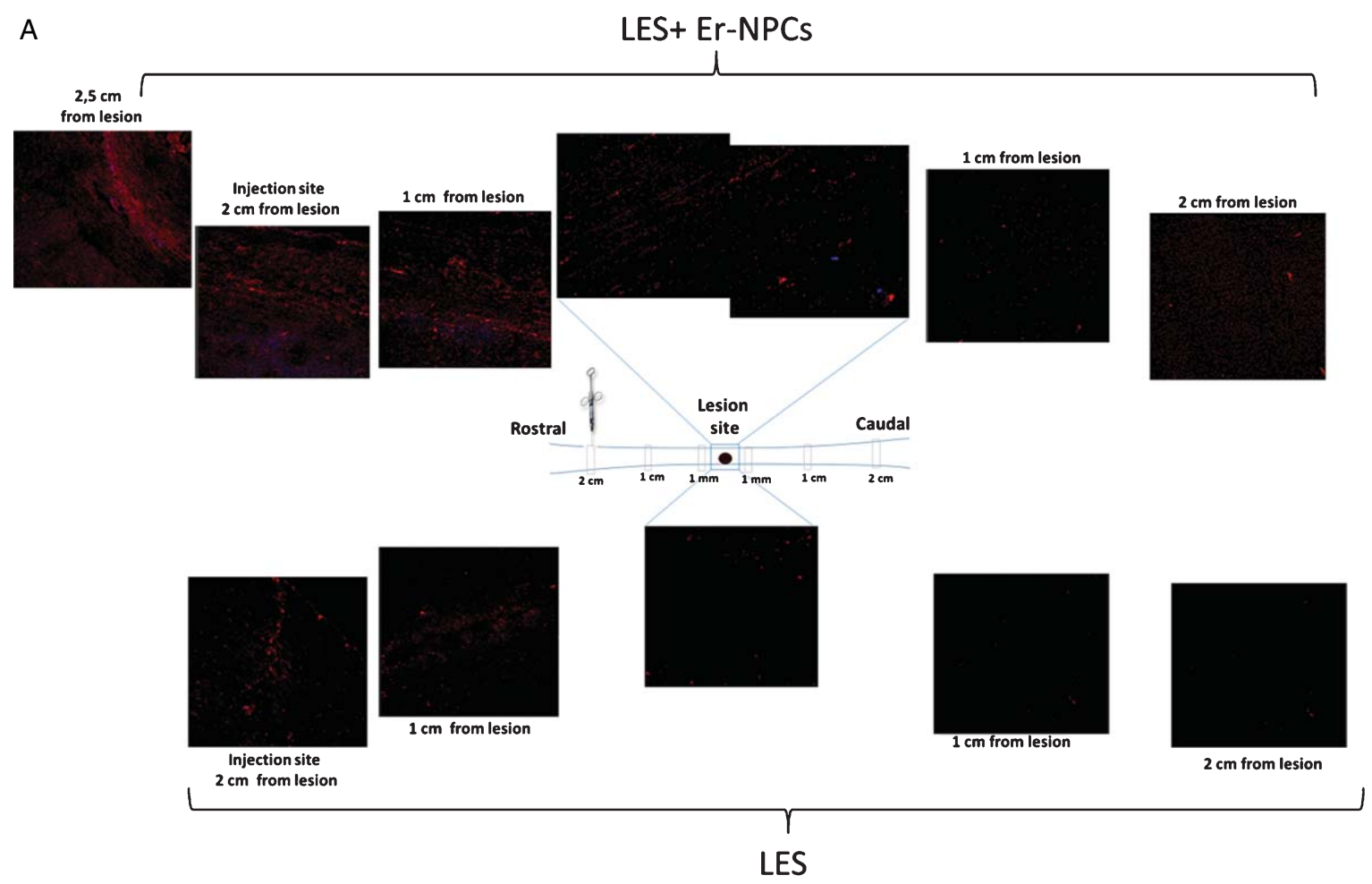

B

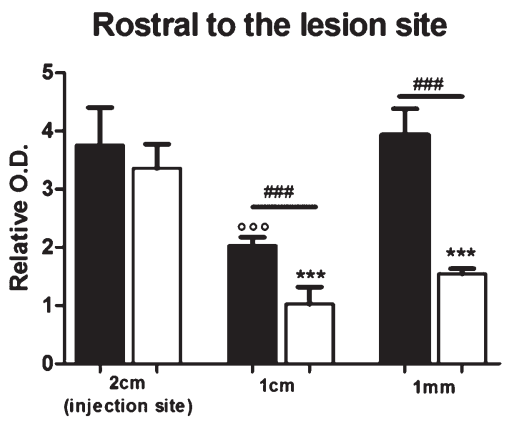

Distance

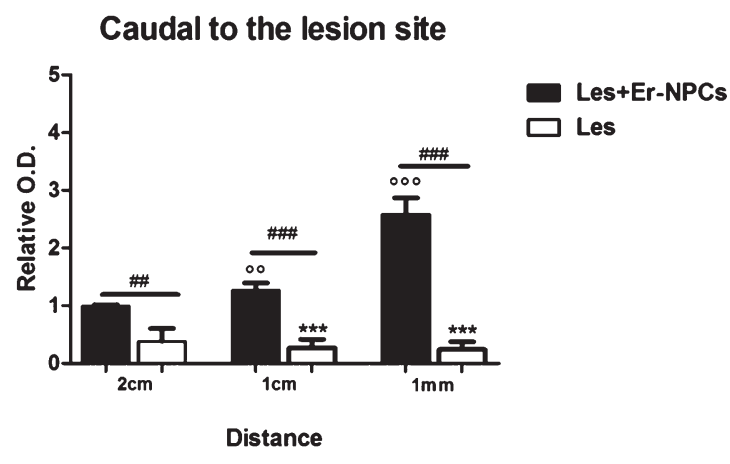

Fig. 8. In vivo axonal transport recovery in spinal cord of animal transplanted or not with Er-NPCs. Panel A. Qualitative image of anterograde axonal transport at 25 days after lesion in PM-NPC treated animals. As described in material and methods section fluororuby was injected at T6/T7 at day 20 after lesioning and animal sacrificed five days later. Schematic reconstruction of spinal cord longitudinal sections of lesioned (below) and lesioned+Er-NPCs (above) treated animals. Er-NPCs were stained with Hoechst (blue). Panel B. Quantification of fluorescence $2 \mathrm{~cm}, 1 \mathrm{~cm}$ and $1 \mathrm{~mm}$ away from the lesion. Sections were taken from animals transplanted or not with Er-NPCs. Quantification was performed in three animals per group 25 days after lesion. We determined the statistical differences by means of an ANOVA test followed by Bonferroni's post-test. $* * p<0.01,{ }^{* * *} p<0.001$ vs saline treatment; ${ }^{\circ} p<0.01 \mathrm{vs} 2 \mathrm{~cm}$ transplanted mice; ${ }^{\circ} p \#<0.001 \mathrm{vs} 1 \mathrm{~cm}$ transplanted mice.

thus, conceivable that the prompt effect of Er-NPCs renders these territories amenable to sustain axonal regrowth as we report here. This is likely the biological base for the highly more trophic cord observed even 10 months after lesioning and transplantation by NMR (Carelli et al., 2015).

Perrin and coworkers transplanted lentiviral transduced human embryonic neural progenitors capable of expressing neurogenin-2 (Perrin et al., 2011) and reported that animal functional recovery correlated with partial restoration of serotonin fiber density caudal to the lesion (Perrin et al., 2011). In addition, immature astrocytes derived from bone marrow stromal cells grafted into the injured spinal cord were able to promote the outgrowth of 5HT-positive fibers since they offered a growth-permissive surface 


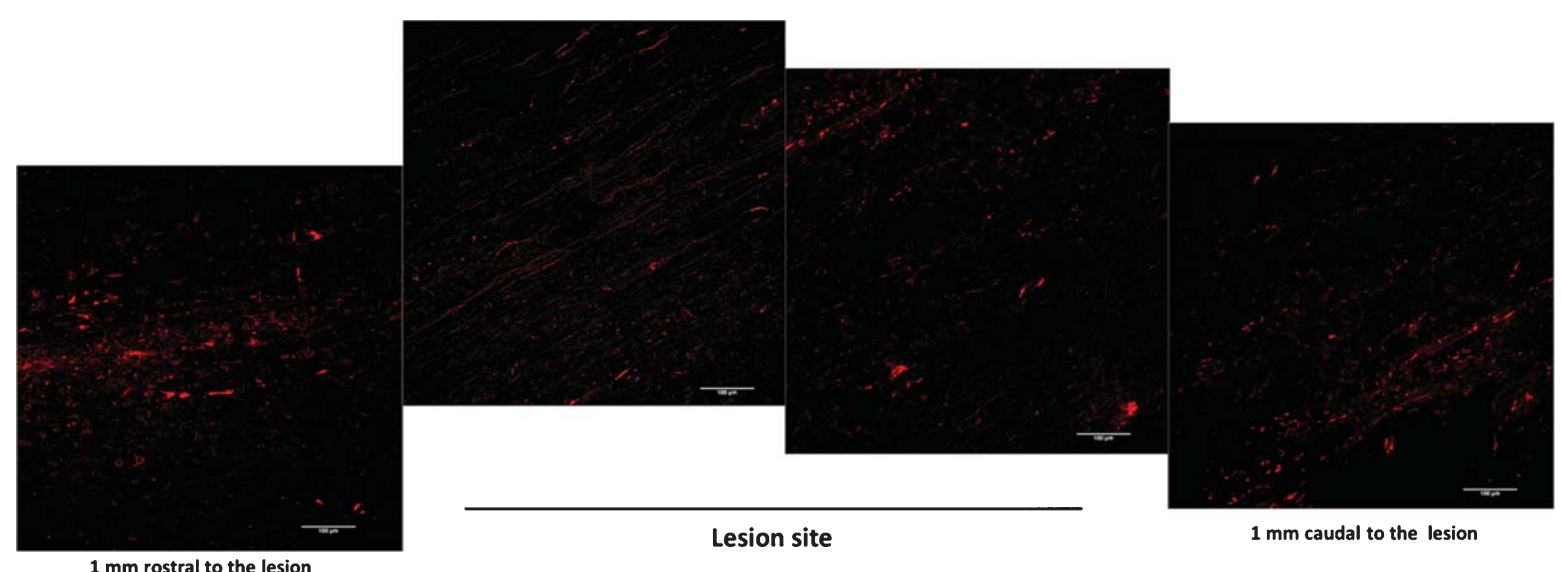

Fig. 9. Detail of anterograde axonal labelling relative to Er-NPCs transplanted animals (at 30 days). The reconstruction is referring to longitudinal sections of lesion site epicenter (T9) and $1 \mathrm{~mm}$ away from the lesion. Scale bars $=100 \mu \mathrm{m}$.

(Hofstetter et al., 2005). The positive effectiveness of stem cells transplants in the injured CNS might be due to the release of trophic factors by the engrafted cells (Martino \& Pluchino, 2006; McTigue et al., 1998; Widenfalk et al., 2001; De Lima et al., 2012). The present study reports that TH-positive fiber density in the ventral portion of the lumbosacral cord of lesioned Er-NPCs treated mice is much higher than in saline-treated lesioned mice. Interestingly, these evidences are in accordance with what has been reported previously in spinal cord lesioned rats acutely treated with rhEPO (Cerri et al., 2012). Here it was reported that exogenous administration of rhEPO increased the preservation of $\mathrm{TH}$ - positive fibers and buttons in the lesioned cord and this corresponded to larger descending spinal and ascending cortical evoked potentials (Cerri et al., 2012). Plasticity and its adaptive changes following injury are among the most studied problems in neuroscience, and there is much evidence that the serotonin and noradrenaline systems are involved in the sublesional changes following traumatic lesions to the cord (Parker, 2000; Jordan et al., 2008; Harkema et al., 2011).

An ideal treatment capable of inducing axon regeneration in the injured central spinal cord should attenuate scarring (Abematsu et al., 2006), the production of growth-inhibitory factors at the lesion site (Ballerman \& Fouad, 2006; Cao et al., 2002) and, at the same time, stimulate axon growth (Tran et al., 2015; Williams et al., 2015; Young, 2015). Er-NPCs could improve the recovery of function and favour axon regeneration likely by supplying a favorable environment and releasing EPO that has powerful anti-inflammatory activity by reducing the expression of inflammatory cytokines and counteracting the invasion by inflammatory cells into the injury site (Gorio et al., 2002; Gorio et al., 2005). This results in the attenuation of secondary degeneration. This results in the enhancement of spared tissue at the injury site with particular protective effects on the reticulospinal tract leading to behavioral recovery. Transplanted Er-NPCs have a higher survival capability in such an unfavorable environment compared to regular adult NSCs. We had previously reported that i.v. infused adult neural stem cells (NSCs), isolated from the subventricular zone (SVZ), are able to reach the injury site and improve the early rate of hindlimb functional recovery, but they are vital for a couple of weeks since at 3 weeks they are phagocytized by macrophages and the process of recovery stops (Bottai et al., 2008). Thus, the effects of Er-NPCs might be a combination of anti-inflammatory and neuroprotective actions that finally result in spinal tissue sparing (Gorio et al., 2002; Gorio et al., 2005) with the supplementation of a positive microenvironment that might be of a key importance in allowing axonal regeneration across the lesion. Further studies are required to elucidate the mechanisms underlying Epo-mediated reduction of the inhibitory properties of the glial scar. In our previous work, we reported that intravenously infused Er-NPCs reach the lesion site where they modify the local microenvironment by reducing the production of pro-inflammatory cytokines (Carelli et al., 2015) and the infiltration of inflammatory cells, such as macrophages and neutrophils, 
which contribute greatly to secondary degeneration (Carelli et al., 2014b; Carelli et al., 2015). Moreover, the local production of growth factors such as BDNF and NGF is increased (Carelli et al., 2015), and this might stimulate neuronal survival and axonal regrowth (Lindsay, 1998; Zhang et al., 2000; Li et al., 2015). Recently it has been reported that embryonic NSCs transplantation in aged mice is able to enhance functional recovery from spinal cord injury by modification of cord microenvironement by inducing the local expression of growth factors, especially HGF (Takano et al., 2017). We also reported recently that the administration of Er-NPCs in a mouse experimental model of Parkinson's disease promoted both the recovery of function and restoration of $\mathrm{TH}$ positive neurons in the substantia nigra (Carelli et al., 2016; Carelli et al., 2017). These curative effects were due to the physiologic release of erythropoietin as the coinjection of the specific inhibitory antibody abrogated the effect of transplanted cells (Carelli et al., 2016; Carelli et al., 2017).

Many evidences show that stem cells implants by themselves are not able to stimulate significant numbers of axons to exit the injury site, and provide only modest improvements in functional outcome (Fitch et al., 2008; De Lima et al., 2012). For these reasons, in order to mediate significant anatomical repair and/or functional improvements, the effects of stem cell implants have been increased with various pharmacological, molecular, or biomaterial approaches that overcome intrinsic or extrinsic inhibitors of axon growth, such as neurotrophin supplementation, chondroitinase $\mathrm{ABC}$, polysialic acid, matrix suspension, or cyclic AMP elevation (Fawcett et al., 2006; Pearse et al., 2004; Iorgulescu et al., 2015; Takami et al., 2002; Flora et al., 2013). Differently, the present report provides new insights into the effects of transplanted adult neural precursors that likely via local physiologic release of EPO, promote neural tissue sparing and axonal regeneration leading to a significant recovery of function. We also suggest that Er-NPCs, and cells with similar properties, may represent good candidates for cellular therapy in neurodegenerative disorders.

\section{Conclusions}

This study shows that Er-NPCs promoted recovery of function after spinal cord injury, accompanied by preservation of myelination and strong re-innervation of the distal cord.

\section{Abbreviations}

Er-NPCs, erythropoietin-releasing neural precursor cells; TH, tyrosine hydroxilase, 5-HT, serotonin; $\beta$-TUBIII, $\beta$-Tubulin III; SCI, spinal cord injury.

\section{Acknowledgments}

The authors acknowledge Drs. Laura Madaschi and Raffaella Adami for outstanding technical contribution and assistance. Dr. Zuzanna Gombalova participated to research when she was visiting student in the Laboratory of Pharmacology, Dept. of Health Sciences, University of Milan, supported by the Erasmus program for $\mathrm{PhD}$ students.

\section{Funding}

The authors acknowledge the economic support of the "Neurogel-en-Marche" Foundation (France) and AUS Niguarda Onlus (Italy) to AG, and Fondazione "Romeo and Enrica Invernizzi" to AMDG.

\section{Author contributions}

Stephana Carelli: conception and design, data analysis and interpretation, manuscript writing. Toniella Giallongo: performed experiments and data analysis. Zuzana Gombalova and Davide Merli: performed experiments. Anna Maria Di Giulio: data analysis and interpretation, financial support, manuscript writing. Alfredo Gorio: conception and design, data analysis and interpretation, financial support, manuscript writing.

\section{Conflict of interest}

All the contributing authors have seen and approved the manuscript, and any authors of this manuscript do not have any conflict of interest to disclose.

\section{Consent for publication}

All authors provide consent for publication of this paper. 


\section{References}

Abematsu, M., Smith, I., \& Nakashima, K. (2006). Mechanisms of neural stem cell fate determination: Extracellular cues and intracellular programs. Curr. Stem Cell Research and Therapy, 1, 267-277.

Ahuja, C.S., Nori, S., Tetreault, L., Wilson, J., Kwon, B., Harrop, J., Choi, D., \& Fehlings, M.G. (2017). Traumatic Spinal Cord Injury-Repair and Regeneration. Neurosurgery, 80(3S): S9S22. doi: 10.1093/neuros/nyw080

Aigner, L., Arber, S., Kapfhammer, J.P., Laux, T., Schneider, C., Botteri, F., Brenner, H.R., \& Caroni, P. (1995). Overexpression of the neural growth-associated protein GAP-43 induces nerve sprouting in the adult nervous system of transgenic mice. Cell, 83, 269-278.

Ballermann, M., \& Fouad K. (2006). Spontaneous locomotor recovery in spinal cord injured rats is accompanied by anatomical plasticity of reticulospinal fibers. European Journal of Neuroscience, 8, 1988-1996. doi: 10.1111/j.14609568.2006.04726.x

Basso, D.M., Fisher, L.C., Anderson, A.J., Jakeman, L.B., Mctigue, D.M, \& Popovich, P.G. (2006). Basso Mouse Scale for locomotion detects differences in recovery after spinal cord injury in five common mouse strains. Journal of Neurotrauma, 23, 635-659. doi: 10.1089/neu.2006.23. 635

Benowitz, L.I., \& Routtenberg, A. (1997). GAP-43: An intrinsic determinant of neuronal development and plasticity. Trends in Neurosciences, 20, 84-91.

Bottai, D., Madaschi, L., Di Giulio, A.M., \& Gorio, A. (2008). Viability-dependent promoting action of adult neural precursors in spinal cord injury. Molecular Medicine, 14, 634-644. doi: 10.2119/2008-00077.Bottai

Cao, Q.L., Howard, R.M., Dennison, J.B., \& Whittemore, S.R. (2002). Differentiation of engrafted neuronal-restricted precursor cells is inhibited in the traumatically injured spinal cord. Experimental Neurology, 177, 349-359.

Carelli, S., Giallongo, T., Gerace, C., De Angelis, A., Basso, M.D., Di Giulio, A.M., \& Gorio, A. (2014a). Neural stem cell transplantation in experimental contusive model of spinal cord injury. Journal of Visualized Experiments, 17(94). doi: $10.3791 / 52141$

Carelli, S., Giallongo, T., Latorre, E., Caremoli, F., Gerace, C., Basso, M.D., Di Giulio, A.M., \& Gorio, A. (2014b). Adult Mouse Post Mortem Neural Precursors survive, differentiate, counteract cytokine production and promote functional recovery after transplantation in experimental traumatic spinal cord. Journal of Stem Cell Research and Transplantation, 1, 1008.

Carelli, S., Giallongo, T., Marfia G., Merli, D., Ottobrini, L., Degrassi, A., Basso, M.D., Di Giulio, A.M., \& Gorio, A. (2015). Exogenous adult postmortem neural precursors attenuate secondary degeneration and promote myelin sparing and functional recovery following experimental spinal cord injury. Cell Transplantation, 24(4), 703-719. doi: $10.3727 / 096368914$ X685140

Carelli, S., Giallongo, T., Viaggi, C., Gombalova, Z., Latorre, E., Mazza, M., Vaglini, F., Di Giulio, A.M., \& Gorio, A. (2016). Grafted neural precursors Integrate into mouse striatum differentiate and promote recovery of function through release of erythropoietin in MPTP-treated mice. ASN Neuro, 27, 8(5). doi: $10.1177 / 1759091416676147$

Carelli, S., Giallongo, T., Viaggi, C., Latorre, E., Gombalova, Z., Raspa, A., Mazza, M., Vaglini, F., Di Giulio, A.M., \& Gorio, A. (2017). Recovery from experimental parkinsonism by intrastriatal application of erythropoietin or EPO-releasing neural precursors. Neuropharmacology, 119, 76-90. doi: 10.1016/j.neuropharm.2017.03.035

Cerri, G., Montagna, M., Madaschi, L., Merli, D., Borroni, P., Baldissera, F., \& Gorio A. (2012). Erythropoietin effect on sensorimotor recovery after contusive spinal cord njury: An electrophysiological study in rats. Neuroscience, 219, 290301. doi: 10.1016/j.neuroscience.2012.05.041

Chaisuksunt, V., Zhang, Y., Anderson, P.N., Campbell, G., Vaudano, E., Schachner, M., \& Lieberman, A.R. (2000). Axonal regeneration from CNS neurons in the cerebellum and brainstem of adult rats: Correlation with the patterns of expression and distribution of messenger RNAs for L1, CHL1, cjun and growth-associated protein-43. Neuroscience, 100, 87-108.

De Lima, S., Koriyama, Y., Kurimoto, T., Oliveira, J.T., Yin, Y., Li, Y., Gilbert, H.Y., Fagiolini, M., Martinez, A.M., \& Benowitz, L. (2012). Full-length axon regeneration in the adult mouse optic nerve and partial recovery of simple visual behaviors. Proceedings of the National Academy of Sciences of the United States of America (PNAS), 109, 9149-9154. doi: 10.1073/pnas.1119449109

Donnelly, C.J., Park, M., Spillane, M., Yoo, S., Pacheco, A., Gomes, C., Vuppalanchi, D., McDonald, M., Kim, H.H., Merianda, T.T., Gallo, G., \& Twiss, J.L. (2013). Axonally Synthesized $\beta$-Actin and GAP-43 Proteins Support Distinct Modes of Axonal Growth. Journal of Neuroscience, 33, 33113322. doi: 10.1523/JNEUROSCI.1722-12.2013

Ertürk, A., Mauch, C.P., Hellal, F., Förstner, F., Keck, T., Becker, K., Jährling, N., Steffens, H., Richter, M., Hübener, M., Kramer, E., Kirchhoff, F., Dodt, H.U., \& Bradke, F. (2012). Three-dimensional imaging of the unsectioned adult spinal cord to assess axon regeneration and glial responses after injury. Nature Medicine, 18, 166-171. doi: 10.1038/nm.2600

Fawcett, J.W. (2006). Novel strategies for protection and repair of the central nervous system. Clinical Medicine, 6, 598-603.

Fehlings, M.G., Cadotte, D.W., \& Fehlings, L.N. (2011). A series of systematic reviews on the treatment of acute spinal cord injury: A foundation for best medical practice. Journal of Neurotrauma, 28, 1329-1333. doi: 10.1089/neu.2011.1955

Fitch, M.T., \& Silver, J. (2008). CNS injury, glial scars, and inflammation: Inhibitory extracellular matrices and regeneration failure. Experimental Neurology, 209, 294-301. doi: 10.1016/j.expneurol.2007.05.014

Flora, G., Joseph, G., Patel, S., Singh, A., Bleicher, D., Barakat, D.J., Louro, J., Fenton, S., Garg, M., Bunge, M.B., \& Pearse, D.D. (2013). Combining neurotrophin-transduced Schwann cells and rolipram to promote functional recovery from subacute spinal cord injury. Cell Transplantation, 22, 2203-2217. doi: 10.3727/096368912X658872

Furlan, J.C., Noonan, V., Cadotte, D.W., \& Fehlings, M.G. (2011). Timing of decompressive surgery of spinal cord after traumatic spinal cord injury: An evidence-based examination of pre-clinical and clinical studies. Journal of Neurotrauma, 28, 1371-1399. doi: 10.1089/neu.2009.1147 
Gorio, A., Gokmen, N., Erbayraktar, S., Yilmaz, O., Madaschi, L., Cichetti, C., Di Giulio, A.M., Vardar, E., Cerami, A., \& Brines, M. (2002). Recombinant human erythropoietin counteracts secondary injury and markedly enhances neurological recovery from experimental spinal cord trauma. Proceedings of the National Academy of Sciences of the United States of America (PNAS), 99, 9450-9455. doi: 10.1073/pnas.142287899

Gorio, A., Madaschi, L., Di Stefano, B., Carelli, S., Di Giulio, A.M., De Biasi, S., Coleman, T., Cerami, A., \& Brines M. (2005). Methylprednisolone neutralizes the beneficial effects of erythropoietin in experimental spinal cord injury. Proceedings of the National Academy of Sciences of the United States of America (PNAS), 102, 16379-16384. doi: 10.1073/pnas.0508479102

Gorio, A., Madaschi, L., Zadra, G., Marfia, G., Cavalieri, B., Bertini, R., \& Di Giulio, A.M. (2007). Reparixin, an inhibitor of CXCR2 function, attenuates inflammatory responses and promotes recovery of function after traumatic lesion to the spinal cord. Journal of Pharmacology and Experimental Therapeutics, 322, 973-981. doi: 10.1124/jpet.107. 123679

Gritti, A., Bonfanti, L., Doetsch, F., Caille, I., Alvarez-Buylla, A., Lim, D.A., Galli, R., Verdugo, J.M., Herrera, D.G., \& Vescovi, A.L. (2002). Multipotent neural stem cells reside into the rostral extension and olfactory bulb of adult rodents. Journal of Neuroscience, 22, 437-445.

Han, Q., Cao, C., Ding, Y., So, K.F., Wu, W., Qu, Y., \& Zhou, L. (2015). Plasticity of motor network and function in the absence of corticospinal projection. Experimental Neurology, 267, 194-208. doi: 10.1016/j.expneurol.2015.03. 008

Harkema, S., Gerasimenko, Y., Hodes, J., Burdick, J., Angeli, C., Chen, Y., Ferreira, C., Willhite, A., Rejc, E., Grossman, R.G., \& Edgerton, V.R. (2011). Effect of epidural stimulation of the lumbosacral spinal cord on voluntary movement, standing, and assisted stepping after motor complete paraplegia: A case study. Lancet, 377, 1938-1947. doi: 10.1016/S01406736(11)60547-3

Hawthorne, A.L., Hu, H., Kundu, B., Steinmetz, M.P., Wylie, C.J., Deneris, E.S., \& Silver J. (2011). The unusual response of serotonergic neurons after CNS Injury: Lack of axonal dieback and enhanced sprouting within the inhibitory environment of the glial scar. Journal Neuroscience, 31, 5605-5616. doi: 10.1523/JNEUROSCI.6663-10.2011

He, Z., \& Koprivica, V. (2004). The Nogo signaling pathway for regeneration block. Annual Review of Neuroscience, 27, 341368. doi: 10.1146/annurev.neuro.27.070203.144340

Hildebrand, C., \& Hahn, R. (1978). Relation between myelin sheath thickness and axon size in spinal cord white matter of some vertebrate species. Journal of the Neurological Sciences, 38, 421-434.

Hofstetter, C.P., Holmström, N.A., Lilja, J.A., Schweinhardt, P., Hao, J., Spenger, C., Wiesenfeld-Hallin, Z., Kurpad, S.N., Frisén, J., \& Olson, L. (2005). Allodynia limits the usefulness of intraspinal neural stem cell grafts; directed differentiation improves outcome. Nature Neuroscience, 8, 346-353. doi: $10.1038 / \mathrm{nn} 1405$

Horan, P.K., Melnicoff, M.J., Jensen, B.D., \& Slezak, S.E. (1990). Fluorescent cell labeling for in vivo and in vitro cell tracking. Methods in Cell Biology, 33, 469-490.
Iorgulescu, J.B., Patel, S.P., Louro, J., Andrade, C.M., Sanchez, A.R., Pearse D.D. (2015). Acute Putrescine Supplementation with Schwann Cell Implantation Improves Sensory and Serotonergic Axon Growth and Functional Recovery in Spinal Cord Injured Rats. Neural Plasticity, 186385. doi: $10.1155 / 2015 / 186385$

Jordan, L.M., Liu, J., Hedlund, P.B., Akay, T., Pearson, K.G. (2008). Descending command systems for the initiation of locomotion in mammals. Brain Research Reviews, 57, 183-191. doi: 10.1016/j.brainresrev.2007.07.019

Lemon, R.N. (2008). Descending pathways in motor control. Annual Review of Neuroscience, 31, 195-218. doi: 10.1146/annurev.neuro.31.060407.125547

Li, S., Wang, X., Gu, Y., Chen, C., Wang, Y., Liu, J., Hu, W., Yu, B., Wang, Y., Ding, F., Liu, Y., \& Gu, X. (2015). Let-7 microRNAs Regulate Peripheral Nerve Regeneration by Targeting Nerve Growth Factor. Molecular Therapy, 23, 790-798. doi: $10.1038 / \mathrm{mt} .2014 .220$

Lindsay, R.M. (1998). Nerve growth factors (NGF, BDNF) enhance axonal regeneration but are not required for survival of adult sensory neurons. Journal of Neuroscience, 8 , 2394-2405.

Liu, J., Akay, T., Hedlund, P.B., Pearson, K.G., \& Jordan, L.M. (2009). Spinal 5-HT7 receptors are critical for alternating activity during locomotion: In vitro neonatal and in vivo adult studies using 5-HT7 receptor knockout mice. Journal of Neurophysiology, 102, 337-348. doi: 10.1152/jn.91239.2008

Liu, S.J., Zou, Y., Belegu, V., Lv, L.Y., Lin, N., Wang, T.Y., McDonald, J.W., Zhou, X., Xia, Q.J., \& Wang, T.H. (2014). Co-grafting of neural stem cells with olfactory en sheathing cells promotes neuronal restoration in traumatic brain injury with an anti-inflammatory mechanism. Journal of Neuroinflammation, 11, 66-75. doi: 10.1186/1742-2094-11-66

Loy, D.N., Talbott, J.F., Onifer, S.M., Mills, M.D., Burke, D.A., Dennison, J.B., Fajardo, L.C., Magnuson, D.S., \& Whittemore, S.R. (2002). Both dorsal and ventral spinal cord pathways contribute to overground locomotion in the adult rat. Experimental of Neurology, 177, 575-580.

Lu, J., Ashwell, K.W., Hayek, R., \& Waite, P. (2001). Fluororuby as a marker for detection of acute axonal injury in rat spinal cord. Brain Research, 915, 118-123.

Marfia, G., Madaschi, L., Marra, F., Menarini, M., Bottai, D., Formenti, A., Bellardita, C., Di Giulio, A.M., Carelli, S., \& Gorio, A. (2011). Adult neural precursors isolated from post mortem brain yield mostly neurons: An erythropoietindependent process. Neurobiology of Disease, 43, 86-98. doi: 10.1016/j.nbd.2011.02.004

Martino, G., \& Pluchino, S. (2006). The therapeutic potential of neural stem cells. Nature Reviews Neuroscience, 7 , 395-406.

McTigue, D.M., Horner, P.J., Stokes, B.T., \& Gage, F.H. (1998). Neurotrophin-3 and brain-derived neurotrophic factor induce oligodendrocyte proliferation and myelination of regenerating axons in the contused adult rat spinal cord. Journal of Neuroscience, 18, 5354-5365.

Meiri, K.F., Pfenninger, K.H., \& Willard, M.B. (1986). Growthassociated protein, GAP-43, a polypeptide that is induced when neurons extend axons, is a component of growth cones and corresponds to pp46, a major polypeptide of a subcellular fraction enriched in growth cones. Proceedings of the 
National Academy of Sciences of the United States of America (PNAS), 83, 3537-3541.

Parker, D. (2000). Spinal-Cord plasticity: Independent and interactive effects of neuromodulator and activity-dependent plasticity. Molecular Neurobiology, 22, 55-80.

Pearse, D.D., Pereira, F.C., Marcillo, A.E., Bates, M.L., Berrocal, Y.A., Filbin, M.T., \& Bunge, M.B. (2004). cAMP and Schwann cells promote axonal growth and functional recovery after spinal cord injury. Nature Medicine, 10, 610-616.

Perrin, F.E., Boniface, G., Serguera, C., Lonjon, N., Serre, A., Prieto, M., Mallet, J., \& Privat, A. (2010). Grafted human embryonic progenitors expressing neurogenin-2 stimulate axonal sprouting and improve motor recovery after severe spinal cord injury. PLoS One, 5(12), e15914. doi: 10.1371/journal.pone.0015914

Pertici, V., Amendola, J., Laurin, J., Gigmes, D., Madaschi, L., Carelli, S., Marqueste, T., Gorio, A., \& Decherchi, P. (2013). The use of poly(N-[2-hydroxypropyl]-methacrylamide) hydrogel to repair a T10 spinal cord hemisection in rat: A behavioural, electrophysiological and anatomical examination. ASN Neuro, 5(2), 149-166. doi: 10.1042/AN20120082

Romanko, M.J., Zhu, C., Bahr, B.A., Blomgren, K., \& Levison, S.W. (2007). Death effector activation in the subventricular zone subsequent to perinatal hypoxia/ischemia. Journal of Neurochemistry, 103, 1121-1131.

Schlayer, H.J., Laaff, H., Peters, T., Woort-Menker, M., Estler, H.C., Karck, U., Schaefer, H.E., \& Decker, K. (1988). Involvement of tumor necrosis factor in endotoxin-triggered neutrophil adherence to sinusoidal endothelial cells of mouse liver and its modulation in acute phase. Journal of Hepatology, 7, 239-249.

Schofield, B.R., Schofield, R.M., Sorensen, K.A., \& Motts, S.D. (2007). On the use of retrograde tracers for identification of axon collaterals with multiple fluorescent retrograde tracers. Neuroscience, 146, 773-783.

Shigyo, M., \& Tohda, C. (2016). Extracellular vimentin is a novel axonal growth facilitator for functional recovery in spinal cord-injured mice. Scientific Reports, 6, 28293. doi: $10.1038 /$ srep28293

Skene, J.H., Jacobson, R.D., Snipes, G.J., McGuire, C.B., Norden, J.J., \& Freeman, J.A. (1986). A protein induced during nerve growth (GAP-43) is a major component of growth-cone membranes. Science, 233, 783-786.
Takami, T., Oudega, M., Bates, M.L., Wood, P.M., Kleitman, N., \& Bunge, M.B. (2002). Schwann cell but not olfactory ensheathing glia transplants improve hindlimb locomotor performance in the moderately contused adult rat thoracic spinal cord. Journal of Neuroscience, 22, 6670-6681.

Takano, M., Kawabata, S., Shibata, S., Yasuda, A., Nori, S., Tsuji, O., Nagoshi, N., Iwanami, A., Ebise, H., Horiuchi, K., Okano, H., Nakamura, M. (2017). Enhanced Functional Recovery from Spinal Cord Injury in Aged Mice after Stem Cell Transplantation through HGF Induction. Stem Cell Reports, 8(3), 509-518. doi: 10.1016/j.stemcr.2017.01.013

Tran, A.P., \& Silver, J. (2015). Neuroscience. Systemically treating spinal cord injury. Science, 348, 285-286. doi: 10.1126/science.aab1615

Verkade, P., Verkleij, A.J., Annaert, W.G., Gispen, W.H., \& Oestreicher, A.B. (1996). Ultrastructural localization of B-50/growth-associated protein-43 to anterogradely transported synaptophysin-positive and calcitonin gene-related peptide-negative vesicles in the regenerating rat sciatic nerve. Neuroscience, 71, 489-505.

Vitellaro-Zuccarello, L., Mazzetti, S., Madaschi, L., Bosisio, P., Gorio, A., \& De Biasi, S. (2007). Erythropoietin-mediated preservation of the white matter in rat spinal cord injury. Neuroscience, 144, 865-877.

Wallace, P.K., Tario, J.D. Jr, Fisher, J.L., Wallace, S.S., Ernstoff, M.S., \& Muirhead, K.A. (2008). Tracking Antigen-Driven Responses by Flow Cytometry: Monitoring Proliferation by Dye Dilution. Cytometry, 73A, 1019-1034. doi: 10.1002/cyto.a.20619

Widenfalk, J., Lundströmer, K., Jubran, M., Brene, S., \& Olson, L. (2001). Neurotrophic factors and receptors in the immature and adult spinal cord after mechanical injury or kainic acid. Journal of Neuroscience, 21, 3457-3475.

Williams, R.R., Henao, M., Pearse, D.D., \& Bunge, M.B. (2015). Permissive Schwann cell graft/spinal cord interfaces for axon regeneration. Cell Transplantation, 24, 115-113. doi: $10.3727 / 096368913 \times 674657$

Young, W. (2014). Spinal Cord regeneration. Cell Transplantation, 23, 573-611. doi: 10.3727/096368914X678427

Zhang, J.Y., Luo, X.G., Xian, G.J., Liu, Z.H., \& Zhou, X.F. (2000). Endogenous BDNF is required for myelination and regeneration of injured sciatic nerve in rodents. European Journal of Neuroscience, 12, 4171-4180. 